\title{
ASSISTÊNCIA À CRIANÇA E AO ADOLESCENTE COM CÂNCER: A FASE DA QUIMIOTERAPIA INTRATECAL
}

\author{
Fernanda Araújo Lemos ${ }^{1}$ \\ Regina Aparecida Garcia de Lima² \\ Débora Falleiros de Mello ${ }^{3}$
}

Lemos FA, Lima RAG, Mello DF. Assistência à criança e ao adolescente com câncer: a fase da quimioterapia intratecal. Rev Latino-am Enfermagem 2004 maio-junho; 12(3):485-93.

O objetivo do presente trabalho é explorar as vivências de crianças e adolescentes com câncer, durante a fase de quimioterapia intratecal, através de abordagem qualitativa com coleta de dados empíricos realizada a partir de entrevista semiestruturada. Participaram do estudo onze crianças/adolescentes que receberam quimioterapia intratecal, na faixa etária de 07 a 16 anos, de ambos os sexos, atendidos em um hospital-escola do interior do estado de São Paulo. Os resultados convergiram para os seguintes temas: rotina da intratecal; medo, dor e fantasias e estratégias de alívio. Este trabalho possibilitou o acesso a informações de real interesse para a assistência às crianças/adolescentes, durante a fase da quimioterapia intratecal, situação tida como uma das mais estressantes. Quanto às implicações para a enfermagem, identificou-se que a informação é vital para crianças/adolescentes com câncer, pois ela poderá minimizar incertezas e sentimentos negativos, levando-os a colaborar e a participar do tratamento.

DESCRITORES: enfermagem pediátrica; quimioterapia; oncologia

\section{CARING FOR CHILDREN AND ADOLESCENTS WITH CANCER: THE INTRATHECAL CHEMOTHERAPY PHASE}

This study aims to explore the experiences of children and adolescents with cancer during the intrathecal chemotherapy phase, by means of a qualitative approach. Empirical data were collected on the basis of semi-structured interviews. Study participants were eleven children/adolescents who received intrathecal chemotherapy, between 07 and 16 years old, from both genders, attended at a hospital school in the interior of São Paulo State, Brazil. Results converged towards the following issues: intrathecal routine; fear, pain and relief fantasies and strategies. This study gave access to important information with a view to caring for children/adolescents during the intrathecal chemotherapy phase, which is considered as one of the most stressing situations. With respect to nursing implications, we identified the vital nature of information for children/adolescents with cancer since this makes it possible to minimize uncertainties and negative feelings and makes them collaborate and participate in treatment.

DESCRIPTORS: pediatric nursing; drug therapy; medical oncology

\section{ATENCIÓN A LOS NIÑOS Y ADOLESCENTES CON CÁNCER: LA ETAPA DE QUIMIOTERAPIA INTRATECAL}

El objetivo del presente trabajo es el de explorar las vivencias de niños y adolescentes con cáncer durante la etapa de quimioterapia intratecal, mediante la aproximación cualitativa con colección de datos empíricos efectuada a partir de entrevista semi-estructurada. Participaron del estudio once niños/adolescentes que recibieron quimioterapia intratecal, entre 07 y 16 años, de ambos los sexos, atendidos en un hospital escuela del interior del Estado de São Paulo. Los resultados convergieron en los siguientes temas: rutina de la intratecal; miedo, dolor, fantasías y estrategias de alivio. Este trabajo posibilitó el acceso a informaciones de real interés para atención a los niños/adolescentes durante la etapa de quimioterapia intratecal, que es considerada una de las más estresantes. Al respecto de las implicaciones para la enfermería, identificamos que la información es vital para niños/adolescentes con cáncer ya que, mediante ella, es posible minimizar incertidumbres y sentimientos negativos, llevándoles a colaborar y participar del tratamiento.

DESCRIPTORES: enfermería pediátrica; quimioterapia; oncología, médica

\footnotetext{
${ }^{1}$ Aluna do Curso de Graduação em Enfermagem; ${ }^{2}$ Orientador, Professor Associado, e-mail: limare@eerp.usp.br; ${ }^{3}$ Professor Doutor. Escola de Enfermagem de Ribeirão Preto, da Universidade de São Paulo, Centro Colaborador da OMS para o desenvolvimento da pesquisa em enfermagem
} 
Ao câncer infantil corresponde um grupo de doenças (tumores sólidos e doenças sistêmicas) que têm em comum a proliferação desordenada e descontrolada de células anormais, comprometendo tecidos e órgãos ${ }^{(1)}$.

As estatísticas sobre incidência do câncer em pacientes menores de 20 anos, nos Estados Unidos, indicam que as leucemias encontram-se entre os tipos mais comuns $(31,4 \%)$, vindo, na seqüência, os tumores de sistema nervoso central (17,6\%), os linfomas (12,4\%), os tumores de tecidos moles $(7,1 \%)$, os tumores do sistema nervoso simpático $(6,6 \%)$, os tumores renais $(6,3 \%)$, os tumores ósseos (5\%) e outros tumores (4,5\%). Quanto à mortalidade, constitui-se na segunda causa de morte entre crianças americanas menores de 15 anos $^{(2)}$.

No Brasil, anualmente, de 12 a 13 mil crianças menores de 14 anos são acometidas por algum tipo de câncer, e destas, cerca de $70 \%$ podem ser consideradas curadas, dependendo da precocidade do diagnóstico. Quanto à mortalidade, apresenta-se como a terceira causa de morte na população abaixo de 14 anos $^{(3)}$.

O aumento da sobrevida de crianças e adolescentes com câncer, que ora vem ocorrendo no Brasil, à semelhança de outros países, é decorrente do tratamento multidisciplinar, ou seja, da utilização de métodos de diagnóstico mais acurados; da evolução dos medicamentos e agentes que proporcionam suporte contra infecções; da utilização de novas modalidades hemoterápicas e dos transplantes de medula óssea; do apoio psicossocial e da nutrição adequada ${ }^{(4)}$. Outro aspecto importante para o aumento da sobrevida é a detecção precoce da doença; no entanto, essa detecção, na maioria das vezes, ainda ocorre de forma acidental.

Dados internacionais revelam que $1 \mathrm{em}$ cada 100.000 adultos jovens será sobrevivente de um câncer na infância ${ }^{(1-2)}$. No Brasil, cerca de 70 a $80 \%$ dos casos envolvendo crianças e jovens com leucemia linfóide aguda têm cura ${ }^{(5)}$.

A terapêutica do câncer é composta, basicamente, por três modalidades: cirurgia, radioterapia e tratamento medicamentoso, incluindo, nesse último tipo, as drogas citostáticas comumente denominadas de quimioterapia

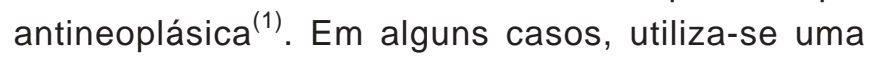
modalidade terapêutica separadamente, e, em outros, pode existir uma combinação de duas ou até das três modalidades. No caso do câncer infantil, a quimioterapia é um importante componente terapêutico, uma vez que a maioria das doenças malignas da infância é sensível a $\mathrm{ela}^{(6)}$. substâncias químicas, isoladas ou combinadas, com o objetivo de tratar as neoplasias malignas, as quais atuam em nível celular, interferindo no seu processo de crescimento e divisão e, por não possuírem especificidade, destróem indistintamente células neoplásicas e normais. As principais vias de administração de quimioterapia, nas crianças e adolescentes, são: endovenosa, subcutânea, intramuscular, oral e intratecal ${ }^{(6)}$.

Utiliza-se a via intratecal porque grande parte dos quimioterápicos não atravessa a barreira hematoliquórica, inviabilizando o tratamento e a profilaxia dos tumores primários ou metastáticos do sistema nervoso central, da leucemia meníngea, da carcinomatose decorrente do câncer de mama, linfoma e rabdomiossarcoma. Essa intervenção requer punção medular realizada por especialista (onco-hematologista ou neurologista), para administração das drogas antineoplásicas diretamente no líquido cefalorraquidiano ${ }^{(6-7)}$.

A técnica utilizada para realização dessa punção consiste na localização do espaço entre as vértebras $L 3$ e L4, criando-se uma linha imaginária entre as cristas ilíacas, direita e esquerda, onde se introduz uma agulha especial para retirada do líquido cefalorraquidiano, em gotas. Após a coleta do líquido para análise de citologia oncótica, é que se introduz o medicamento, lentamente, sempre testando o fluxo a cada mililitro injetado. Para o sucesso do procedimento, a imobilização e o posicionamento do paciente são fundamentais ${ }^{(7)}$.

O objetivo desse tratamento é expor o líquor, as meninges e o sistema nervoso central a uma concentração efetiva de antineoplásico. As aplicações podem ser diárias, a cada três dias, ou semanalmente, dependendo do protocolo adotado. Antes e após as aplicações, recomenda-se aumento da ingesta hídrica e repouso, preferencialmente em decúbito dorsal, nas duas horas seguintes ao procedimento, para prevenir cefaléia. As reações mais esperadas são: cefaléia, náuseas e febre, porém podem ocorrer manifestações mais sérias, relacionadas à neurotoxidade e meningite química, ocasionadas pelas drogas, como rigidez de nuca, vômitos, paresias, dor lombar, confusão mental, irritabilidade, vertigem, sonolência e convulsões ${ }^{(6)}$.

$\mathrm{Na}$ assistência à criança e ao adolescente com câncer, observamos que a administração da quimioterapia intratecal é uma das situações que mais causam dor, medo, sofrimento, ansiedade e estresse, tanto nas crianças/adolescentes quanto nos seus familiares.

Pela complexidade do câncer, o tratamento deve ser abrangente, merecendo atenção não só as 
necessidades físicas, como também as necessidades psicológicas e sociais, incluindo personalização da assistência, promoção de cuidados atraumáticos e direito à informação. Nesse sentido, disponibilizar informações sobre o câncer e fornecer suporte social são atitudes que poderão, também, promover a auto-estima de crianças e adolescentes, ajudando-os a enfrentar a doença e a buscar uma vida mais normal ${ }^{(8)}$.

\section{ESTABELECENDO O OBJETIVO E A METODOLOGIA}

Considerando que a administração da quimioterapia intratecal tem sido mencionada como um dos procedimentos que mais causam dor e ansiedade, 0 objetivo deste estudo é explorar as vivências das crianças e dos adolescentes durante essa fase.

Este estudo é de natureza qualitativa, abordagem escolhida por ser a mais apropriada para responder às questões que formulamos "Conte como foi a quimioterapia intratecal" e "Quais informações você daria às crianças que vão começar o tratamento intratecal?".

A abordagem qualitativa é particularmente valiosa, uma vez que permite descobrir e entender o significado de eventos e práticas sociais, assim como das percepções e ações individuais ${ }^{(9)}$. Os métodos qualitativos são amplamente utilizados nas pesquisas em enfermagem porque possibilitam aos pesquisadores interpretarem as diferentes maneiras que as pessoas vivenciam e experienciam processos de saúde e doença ${ }^{(10)}$.

Em observância à legislação que regulamenta a pesquisa em seres humanos ${ }^{(11)}$, encaminhamos 0 protocolo de pesquisa ao Comitê de Ética em Pesquisa da instituição onde a pesquisa de campo seria realizada, em maio de 2001, sendo ele aprovado em 02/07/2001, Processo HCRP № 4100/2001.
A instituição selecionada para a realização do estudo foi um hospital-escola, referência para a assistência à criança e ao adolescente com doenças oncohematológicas, situado em um município do interior do estado de São Paulo.

Participaram deste estudo crianças e adolescentes, na faixa etária de 7 a 16 anos, de ambos os sexos e que receberam quimioterapia intratecal. A escolha dessa faixa etária deveu-se ao fato de seus integrantes encontrarem-se na fase do pensamento lógico e coerente, conseguindo comunicar verbalmente suas idéias e dar significado às suas experiências ${ }^{(12)}$. Buscamos os sujeitos desta pesquisa no "Grupo de Crianças e Adolescentes", que se reunia semanalmente no Ambulatório de Psico-Oncologia Pediátrica do hospitalescola.

Durante os meses de agosto a novembro de 2001, semanalmente, buscávamos no grupo aquelas que preenchiam nosso critério de inclusão: faixa etária de 7 a 16 anos e que tinham recebido quimioterapia intratecal. Onze participantes do "Grupo de Crianças e Adolescentes" preencheram esses critérios, sendo essa a amostra.

Ao identificarmos essas crianças e os adolescentes solicitávamos às mães ou responsáveis autorização para que eles participassem do estudo, e todas concordaram; a seguir, fizemos o convite às crianças/ adolescentes e todas aceitaram participar do estudo. A partir daí, agendávamos o dia e o horário da entrevista com a criança/adolescente e ela sempre ocorreu durante os retornos ambulatoriais.

Ao iniciarmos a entrevista, era informado a mãe que ela poderia permanecer com seu filho durante a etapa de coleta de dados, algumas assim o fizeram.

$\mathrm{Na}$ Tabela 1, a seguir, estão algumas características das crianças e dos adolescentes que participaram do estudo.

Tabela 1 - Características das crianças e adolescentes que vivenciaram a quimioterapia intratecal. Ribeirão Preto, 2001

\begin{tabular}{|c|c|c|c|c|c|c|c|}
\hline Identificação & Idade & Sexo & Escolaridade & Procedência & \multicolumn{2}{|c|}{ Diagnóstico } & $\begin{array}{c}\text { Data do } \\
\text { diagnóstico }\end{array}$ \\
\hline E1 & 11 anos & feminino & $5^{\text {a }}$ série & São Sebastião do Paraíso-MG & L.L.A. ${ }^{*}$ & & 20/08/1998 \\
\hline E2 & 10 anos & masculino & 4a série & Franca-SP & L.L.A. & & $11 / 10 / 2000$ \\
\hline E3 & 13 anos & masculino & 6ª série & Monte Santo-MG & $\begin{array}{l}\text { Linfoma } \\
\text { Hodgkin }\end{array}$ & não- & $21 / 09 / 1999$ \\
\hline E4 & 7 anos & feminino & 1as série & Pedregulho-SP & L.L.A. & & $29 / 01 / 2001$ \\
\hline E5 & 11 anos & masculino & $3^{\underline{a}}$ série & Guaxupé-MG & L.L.A. & & $20 / 02 / 2001$ \\
\hline E6 & 13 anos & masculino & 5a série & Ribeirão Preto-SP & L.L.A. & & $18 / 06 / 1999$ \\
\hline E7 & 16 anos & masculino & $8^{\underline{a}}$ série & Brodósqui-SP & L.L.A. & & $25 / 03 / 1999$ \\
\hline E8 & 14 anos & masculino & $8^{\text {a }}$ série & Ibaté-SP & $\begin{array}{l}\text { Linfoma } \\
\text { Hodgkin }\end{array}$ & não- & $24 / 05 / 1999$ \\
\hline E9 & 13 anos & masculino & $5^{\text {a }}$ série & Matão-SP & L.L.A. & & 26/09/1998 \\
\hline E10 & 13 anos & masculino & 7aㅗ série & São Joaquim da Barra-SP & L.L.A. & & $18 / 08 / 2001$ \\
\hline E11 & 11 anos & masculino & $2^{\text {a }}$ série & Guará-SP & L.L.A. & & $28 / 03 / 2001$ \\
\hline
\end{tabular}

*Leucemia Linfóide Aguda 
Para assegurar a privacidade e garantir o sigilo dos dados, utilizamos um sistema de codificação para as entrevistas, no qual os nomes foram substituídos por letra e números. A primeira criança passou a ser identificada como E1, a segunda como E2, e assim sucessivamente.

A bolsista de iniciação científica coletou os dados das crianças e adolescentes que receberam quimioterapia intratecal, por meio de entrevista semi-estruturada, gravada. A opção por essa técnica ocorreu por ela possibilitar maior flexibilidade, profundidade ${ }^{(13)}$, interação e reflexão ${ }^{(14)}$, ou seja, a partir de um esquema básico, o entrevistador tem liberdade para adaptações, buscando fugir de respostas puramente afirmativas ou negativas.

A estrutura básica da entrevista constou de duas partes: a primeira, de identificação, continha informações sobre sexo, idade, grau de escolaridade, procedência, diagnóstico e protocolo de quimioterapia intratecal. A segunda consistia de duas questões: "Conte como foi a quimioterapia intratecal" e "Quais informações você daria às crianças que vão começar o tratamento intratecal?"

Transcrevemos as entrevistas, procurando, também, registrar as inflexões, o tom, as pausas e hesitações, a fim de retratar o conteúdo verbal e não-verbal. Para o registro do conteúdo não-verbal, buscamos anotações no diário de campo. Quanto aos dados de identificação (registro, diagnóstico, data do diagnóstico e protocolo da intratecal), nós os coletamos nos prontuários dos pacientes.

A análise dos dados seguiu os seguintes passos: ordenação, classificação e análise final dos dados ${ }^{(15)}$. Iniciamos a primeira etapa - ordenação dos dados transcrevendo e digitando, na íntegra, todo material empírico, corrigindo erros grosseiros da língua portuguesa, tomando o cuidado de não modificar as características básicas do texto e de seu significado expresso, conduta que adotamos para possibilitar sua maior compreensão e clareza.

Após esse procedimento, iniciamos a leitura das entrevistas, procurando apreender, por meio das falas das crianças/adolescentes, como estes vivenciaram a quimioterapia intratecal. Assim, analisamos cada entrevista por parte, buscando identificar as idéias centrais, temas, regularidades e singularidades.

Submetemos todas as entrevistas a esse mesmo procedimento, separadamente, e, ao final, obtivemos 18 agrupamentos que, posteriormente, foram reagrupados em três temas: rotina da intratecal; medo, dor e fantasia e estratégias de alívio.

\section{RESULTADOS E DISCUSSÃO}

As entrevistas com as crianças e adolescentes permitiram-nos perceber que eles são capazes de descrever a rotina do procedimento, de manifestar sentimentos de medo e dor, de indicar estratégias de alívio, criando, também, suas próprias fantasias.

Rotina da intratecal

As crianças e os adolescentes mostraram-se informados sobre o procedimento, detalhando a rotina da intratecal. A descrição pormenorizada do procedimento constou de todos os depoimentos, e os passos por eles apresentados seguem a seqüência encontrada na literatura ${ }^{(7)}$. Para exemplificar, transcrevemos os seguintes relatos:

Primeiro eu pego, passo pela consulta, eles colhem sangue; aí, depois, quando acaba de consultar, manda eu pra sala de líquor; a gente chega lá e depois o médico chama; aí, a gente deita numa maca, tem que ficar encolhido, aí eles pegam e enfiam aquela agulhona [risos] nas costa e doí (E9).

Ah! se eu lembro. Primeiro você deita assim [curva as costas] na cama ou na maca, tem que ficar muito encolhido, eles enfiam uma agulha na sua coluna, aí, depois, ele tira o líquido e injeta três remédio, aí acabou. E o remédio é muito dolorido mesmo (E8).

Eles pedem pra você deitar na cama, ficar de costas pra pessoa que vai colher, eles enfiam uma agulha maior e dentro desta agulha eles enfiam outra por onde que eles vão retirar um pouco de líquor pra fazer análise, e o mesmo tantinho que eles tiram de líquor eles colocam de quimioterapia (E7).

Com a chegada da doença, a criança percebe que esse evento interfere na sua vida e na do seu núcleo familiar, ocasionando mudanças no cotidiano de ambos. Para a criança, o início do tratamento indica que terá que se submeter a uma série de procedimentos desconhecidos e dolorosos ${ }^{(16)}$.

Observamos que a doença coloca a criança/ adolescente em contato com exames, procedimentos e aparelhos e palavras desconhecidas, como também com termos incompreensíveis. Os trechos abaixo podem exemplificar tal situação:

Eu chegava lá, eles explicavam, punha a agulha no lugar, eles olhavam assim, passava um álcool lá amarelo, ah! álcool assim anestésico, aí ele pegava explicava pra mim como que ... Ele olhava no lugar, aí eu deitava lá ficava encolhido, né; aí, enfiava e eu falava: ai [com uma intensidade forte, quase gritando], aí doía e, depois, na 
hora que eu acostumei, só falava: ai [falando em tom normal], e ficava só [interrompeu o pensamento], não doía mais... só na hora de entrar, pronto (E2).

É, o médico explicou como é que era, que ia passar um... um... uma anestesia pra não doer muito, pra mim foi chocante assim, né; pra mim eu falei assim: nossa, vai doer pra caramba, porque é na espinha né (E9).

O que eles descrevem como sendo 'álcool anestésico' ou 'anestesia', é um anestésico tópico, a lidocaína e pilocaína*, usado para causar perda temporária da sensibilidade ou dormência na região de aplicação ou próximo dela.

Assim, frente à necessidade de conviverem com uma doença que exige retornos e internações freqüentes, a criança e o adolescente passam a se familiarizar com os procedimentos, nomes dos medicamentos, apropriando-se do vocabulário técnico.

Eles me sedavam porque senão eu não deixava fazer, eu ficava mexendo, aí eu ficava com medo e mexia, aí eles tinham que me sedar. Doía muito, aí eles me levavam lá pra cima e sedava, aí já fui acostumando, aí acostumou, nem precisava, nem doía mais, nem sentia coisa (E2).

A primeira vez teve que anestesiar eu, porque eu sentia doer muito, aí eu ficava mexendo, não deixei ele fazer não, o primeiro dia (E5).

Alguns relatos mostram a identificação do paciente com algum profissional da sala de líquor; pessoas que, de alguma forma, marcaram positivamente suas vidas, como mostram as falas a seguir:

Eu cheguei, tem uma mulher [a técnica da sala de líquor] que fica lá, eu peguei bastante amizade com ela; acho que todo mundo que passa por lá, deve falar dela; ela é uma pessoa especial, ela pegou, explicou direitinho o que era, o que tinha que fazer, eu peguei né, se tem que fazer, vamos lá (E7).

Para fazer a intratecal só o professor, parece que ele tem a mira certinha, aí ele vai lá e já pega, é um japonês alto assim, muito legal (E9).

Outro aspecto ressaltado, durante as entrevistas, relaciona-se às complicações e intercorrências da intratecal.

Uma vez até pegou um nervo da minha perna né, ficava pulando e eu não conseguia nem mexer a perna, só depois de uns vinte minutos passou tudo. Aí ficou tudo normal. Eu me senti bem ruim, viu, eu não conseguia nem pôr o pé no chão e ao andar repuxava a perna (E8).

Os depoimentos abordam os efeitos colaterais da quimioterapia intratecal de forma amena e tolerante, quando comparados aos efeitos colaterais causados pela quimioterapia endovenosa e/ou radioterapia, também experimentados por eles. Busca-se evitá-los com a ingestão de antieméticos, repouso e reposição hídrica. Para exemplificar:

Reação momentânea eu não sentia nenhuma, mas depois é quimioterapia né, ainda por cima na cabeça, mal do estômago de vez em quando pode sentir, mesmo quimioterapia normal eu não costumo passar mal, aí então uma coisa que pode acontecer é você passar mal do estômago, mas tem remédio, os médicos dão, é só pedir o 'sofram', eles dão em comprimido, você toma. Outra coisa que pode acontecer de ruim é a dor de cabeça; pra evitar, você tem que tomar bastante líquido antes e bastante líquido depois, procurar ficar deitado, não fazer movimento brusco, assim de levantar rápido. Isso evita bastante isso, eu tive dor de cabeça uma vez só e é uma dor de cabeça muito ruim. Não é uma dor de cabeça convencional, ela é diferente, parece uma pressão assim [leva as mãos na lateral da cabeça e comprime], então se a pessoa pode evitar isso tomando bastante água, ficando deitado o tempo todo, seria bom (E7).

Bom, antes de fazer, geralmente a pessoa vem aqui de manhã. Na noite do dia anterior, no dia anterior inteiro, bebe bastante líquido, água, bastante líquido, mas muito mesmo, depois que fizer continua bebendo bastante líquido, isso evita de dar dor de cabeça. Eu já percebi isso, muito líquido mesmo, muito que eu falo é pra mais de dois litros, então quanto mais bebe, mais difícil vai ser de você ter uma eventual dor de cabeça e também, depois de fazer, procurar ficar mais quieto, não ficar com a cabeça levantada, isso também evita a dor de cabeça, que é uma coisa que pode acontece $(E 7)$.

Outros descreveram, como mais freqüentes, as náuseas e os vômitos, referindo-se a eles como estressantes e incômodos efeitos colaterais. Ah! Acho que durante todo o momento que eu ficava lá dentro, todo momento era difícil, porque fazer intratecal já é uma coisa difícil e ficar lá não é bom, depois ainda você fica enjoado depois que sai de lá, vomita e não quer comer, fica enjoado pra caramba, vomita aquelas coisa amarela, 'argh' [faz uma cara de nojo] (E6).

Medo, dor e fantasia

Os dados revelam sensações, como medo e dor, comuns a todos os entrevistados. O medo de 'quebrar a agulha' nas costas e da incerteza do que vai ser feito, a 'dor da picada' e a sensação de 'fisgada na perna' são sensações manifestadas em vários relatos.

Ah! é assim, eu penso se eu mexer assim, eu tenho medo da agulha quebrar lá dentro assim, também dói bastante, demora

* Informação fornecida pelo responsável pela sala de líquor 
um pouco, sofre um pouquinho (E9).

As primeiras vezes sentia assim tipo um choque nas minhas perna, a hora que eles enfiavam a agulha, um choque assim daqui pra baixo [mostra o meio das costas para baixo], no meio da coluna pra baixo (E6).

Mesmo que os profissionais empenhem-se em orientar a criança, explicando-Ihe o procedimento em linguagem simples, o medo do desconhecido pode permanecer, como mencionado:

Na verdade eu não lembro exatamente da primeira, mas o medo é não saber ao certo o que vai acontecer, apesar deles explicarem tudo, não saber se é daquele jeitinho mesmo, é na hora da picada, uma coisa muito estranha, um sentimento que eu nunca tinha sentido (E7).

A ausência de informações sobre os procedimentos, ao invés de poupar ou proteger a criança, dificulta e/ou impede a sua organização pessoal frente à doença $^{(17)}$, como podemos observar no seguinte trecho:

Eu acho muito ruim viu, eles deveriam explicar mais ou menos como é o exame, que é dolorido, tudo mais, muito ruim vim pra cá sem sabe o que vai fazer (E8).

Trabalho realizado com adolescentes com câncer mostrou que a punção de medula óssea e a intratecal foram descritas como os procedimentos mais dolorosos, situação também encontrada em nossa pesquisa, conforme mencionado abaixo ${ }^{(18)}$ :

... o pior momento pra mim é fazer o exame das costas e da bacia, o mielograma (E5).

O sofrimento e as fantasias relacionadas ao tratamento e aos procedimentos têm uma dimensão maior do que a própria dor física do câncer, como apresentado a seguir.

Eu ficava com medo que eu não podia andar mais. Eu pensei assim que se agulha pegasse meu nervo eu não podia andar mais (E11).

Geralmente acontece então o impacto inicial... o medo que você já cria na cabeça, uma aversão aquilo (E7).

... e o medo, a dor, isso é uma coisa normal e todo o ser humano tem que ter ansiedade, medo porque se não tiver não é uma pessoa normal; medo todo mundo tem. Medo do tratamento não dar certo, da intratecal e da doença acabar voltando (E6).

Os momentos em que as crianças revelaram maior tensão, ansiedade e medo foram aqueles relacionados às 'picadas', principalmente nas situações em que houve necessidade de mais de uma 'picada', pois não se conseguia achar o local correto de imediato.

Na fase da intratecal, foi uma vez que foi uma médica, eu nunca tinha visto aquela médica, ela tinha me furado umas, umas oito vezes parece, ela tinha me furado e não conseguia achar a espinha, não conseguia, aí minha mãe falava: chama o professor, que ele consegue. Não, eu sou a médica dele, eu que vou fazer, e eu lá sofrendo, sofrendo, aí veio uma enfermeira japonesa e falou: calma, calma, nós vamos chamar o professor, aí chamou o professor (E9).

Foi uma vez que eu fui fazer com um residente, ele furou umas quatro vezes, eu pedi o professor, ele não quis chamar e falou que ia dar certo; na quinta vez ainda não deu certo, e ele mandou voltar no outro dia, aí eu falei com a doutora C., daí ela pegou o professor e agora toda vez que eu vou fazer pede o professor (E8).

Estes relatos mostram, além da dor de várias picadas, a indignação de não serem ouvidos e de não serem respeitados. É fundamental ouvir a criança quando esta manifesta que algo a perturba, porque essa atitude pode minimizar sentimentos de ansiedade e estresse.

As crianças/adolescentes relatam, ainda, que tudo acontece muito de repente, a descoberta da doença, as internações e os procedimentos invasivos. Diante de uma realidade traumática como essa, acabam fantasiando, abusando do seu imaginário. Alguns relatos mostram o que eles imaginavam ser a intratrecal.

A primeira vez eu pensei assim que era um raio $x$, quando os médicos não tinham explicado ainda, eu pensava que não ia doer tanto, eu pensava que era tipo um raio $x$, um exame qualquer (E9).

Diante da doença, a criança, muitas vezes, lança mão de mecanismos de defesa e usa a fantasia para superar situações para as quais não está preparada ${ }^{(19)}$, como exemplo:

Ah! não sei... imaginava que era na veia, um exame na veia, daí eles me deitaram na cama e ficou um monte de médico em volta de mim, fizeram tudo, não vi mais nada, na hora que eu fui ver já tinha terminado, foi a primeira vez (E8).

O dia que eu tava com essa doença lá na minha cidade, na outra, eu tirei líquido do pulmão, aí eu pensei que a intratecal era tirar mais líquido do pulmão (E11).

Alguns fantasiaram com base em comentários que ouviram de outros pais e de outras crianças, como mencionado a seguir:

Ah, porque tem um menino lá de Matão, ele também faz tratamento aqui, já acabou e ele vinha com o pai dele. A primeira vez ele veio com o pai dele fazer intratecal e o pai dele não agüentou ver os médicos furando as costas dele e o pai dele reagiu né, falou que não ia fazer mais nada, começou a bater lá nos médicos..., ele pegou parece que ele caiu, desmaiou, uma coisa assim, ele acabou falecendo (E9).

Ah! de intratecal bem não né, já ouvi pessoas que ficaram mancas por causa dela, nada comprovado, as mães que falam, mas 
isso é relevante, os médicos não confirmaram nada disso, então não se sabe ao certo, mas que dá medo dá [risos] (E7).

Os aspectos do tratamento e da doença devem ser discutidos com a criança e o adolescente, uma vez que a falta de informações pode fomentar dúvidas que, por sua vez, darão margem a fantasias e equívocos.

Estratégias de alívio

As crianças buscam alternativas para amenizar o sofrimento na companhia dos pais, no apoio dos profissionais e na fé em Deus.

O maior suporte para o enfrentamento de situações vivenciadas com o câncer vem da família, especialmente das mães, que assumem a rotina dos retornos ambulatoriais, internações, cuidados com medicações, horários dos remédios e intercorrências ${ }^{(20)}$. Esses suportes também foram mencionados pelas crianças e adolescentes entrevistados, como podemos observar nos relatos:

Ah! eu começo a conversar com eles também, né, com os médicos, que ficam lá ajudando a gente [a mãe, para não interromper a fala do filho, faz um sinal de aperto com as mãos]. É, eu também ficava apertando a mão da minha mãe assim [pega a mão da mãe e aperta com força], tem hora que eu mordia a mão da minha mãe assim [risos], aí ela dava uma fralda pra mim, aí eu mordia a fralda porque dói bastante, sinceramente dói bastante (E9).

Ah! ela [mãe] fica segurando a cabeça, tem que ficar bem encolhido mesmo, tem que abaixar a cabeça, ela ajuda, enquanto eu seguro as perna, ela segura a cabeça, assim vai (E8).

A comunicação, no momento da intratecal, também é uma estratégia utilizada como possibilidade de controle do que está sendo realizado, propiciando a participação ativa do paciente, trazendo-Ihe alívio. Para exemplificar, apresentamos o seguinte depoimento:

Isso eu pedia para o médico explicar, vão supor eu falo assim: quando você pôr a agulha me avisa, porque se enfiar de uma vez e eu tiver distraído aí na hora repuxa, o músculo contrai e a agulha não entra, aí tem que picar de novo. Agora se eu peço pra ele me explicar, falar quando ele vai enfiar a agulha, quando ele vai injetar o remédio, o momento que tá tirando, eu vou perguntando pra ele: tá saindo já o líquor? Não, eu ainda não achei, aí ele enfiava mais um pouquinho: e agora já achou? Agora achei, tá saindo. É um modo de amenizar, ficar tranqüilo, sabendo o que eles estão fazendo, se tá dando certo e ao mesmo tempo conversar saber o que está acontecendo com você (E7).

Estudos mostram que os pacientes encontram na espiritualidade, seja em crenças ou orações, um meio para enfrentar os desafios da doença ${ }^{(21-23)}$. Essa conduta também, foi mencionada pelos entrevistados.

Primeiramente eu acho que tem que ter muita fé em Deus, que sem Ele a gente não é nada e ter fé que um dia vai passar e que ele vai me ajudar a pular essas pedras. Ter muita força de vontade de fazer esse tratamento. Eu só penso em Deus e falo: oh! meu Deus, me ajuda, passa essa fase de tratamento, que eu vou conseguir passar, em Teu nome eu vou conseguir passar, eu penso primeiramente em Deus. É a maior força (E9).

O trabalho da equipe multidisciplinar deve ultrapassar os objetivos unicamente médicos relacionados à luta contra doença, isto é, deve promover condições para que a criança reconheça o que está acontecendo com ela, para que, a partir daí, possa entender o sentido e o significado da sua doença, criando soluções frente a essa nova circunstância de sua vida. Identificamos, nas entrevistas, essa possibilidade.

Tinha uns que segurava minha mão e falava pra mim apertar a mão deles e a dor que eu tava sentindo passa pra mão e não ficar mexendo, que se eles errassem poderia dar alguma complicação. Quando ele enfiava a agulha, tinha um que ficava lá e mandava pegar a mão dele e apertar com toda a força, aí ficava melhor, parecia que doía um pouco menos, mas doía ainda (E6).

Eles falam: fica quietinho, já tá terminando, não precisa ter pressa, relaxa, eles falam. A B. [funcionária da sala de líquor] ajuda muito nós lá também (E8).

Eles tentam, assim, animar, pra criança não perceber o que tá acontecendo assim, pra não saber que dói muito aquilo, sabe? Eles brincam, contam piada, essas coisa (E9).

São inúmeras as evidências de que a criança de qualquer idade e em qualquer nível de desenvolvimento cognitivo-emocional é capaz de compreender as informações sobre sua doença e seu tratamento, e participar ativamente das situações que a envolvem ${ }^{(21-22)}$. Essa evidência pode ser identificada nas seguintes situações:

A intratecal é um tratamento para que a doença não se desenvolva pra cabeça, porque se for pra cabeça aí fica mais difícil de curá-la. Por exemplo, eu tomei acho que 8 meses de intratecal, de duas em duas semanas, aí durante 8 meses eu fiquei tomando, aí parou. Depois eu fiz 9 seção de rádio, aí parou (E6).

... eles utilizam a intratecal, a explicação que me foi dada, é porque a cabeça tem um sistema de defesa muito forte e a quimioterapia não consegue chegar lá, aí pode ter células de leucemia na cabeça e desse modo é mais fácil da quimioterapia chegar lá e exterminar o que pode ter (E7).

Sob o olhar da criança e do adolescente, o hospital tem uma característica de dualidade, ao mesmo 
tempo em que traz sofrimento, também representa um espaço de cura, aonde vão para fazer o tratamento e os exames, buscando salvar suas vidas e trazer a sua saúde ${ }^{(22)}$. Para exemplificar, destacamos os seguintes trechos:

Bom, primeira coisa é que se a pessoa tá lá é porque ela quer se curar e se ela fizer o tratamento de acordo, ela vai conseguir. Então se tem que passar por isso não tem como desviar, o que ela pode tentar fazer é ficar o mais relaxado possível pra tentar amenizar as dores, a reação pós-químio (E7).

Ah! A intratecal precisa pra você melhorar seu tratamento, seu dia-a-dia e pra doença não voltar mais, porque não tem outra escolha, porque se você ficar sem fazer, você pode chegar até à morte (E6).

Foi uma experiência chata que eu tive que passar né, uma das coisas que eu acho importante ressaltar é que é preciso ser feito, não tem como deixar isso de lado, tem que fazer e passa, não é um bicho de sete cabeças, sabendo lidar bem, num instantinho passa, e você nem percebeu como é difícil (E7).

\section{CONSIDERAÇÕES GERAIS}

$\mathrm{Na}$ assistência à criança e ao adolescente com câncer, a quimioterapia intratecal é uma das situações que mais causam dor, sofrimento, ansiedade e estresse, tanto nas crianças/adolescentes, quanto nos seus familiares. Assim, este estudo fornece subsídios para a apreensão desse momento singular de suas vidas, revelado a partir de suas próprias vivências.

Observamos que as crianças e os adolescentes mostraram-se informados sobre o procedimento e a rotina da intratecal, descrevendo-os detalhadamente; também relataram as complicações e intercorrências, enfocando os efeitos colaterais. Identificamos, no entanto, descrições fantasiosas do procedimento. As situações de medo e dor, comuns em todas as entrevistas, foram repetidamente

\section{REFERÊNCIAS BIBLIOGRÁFICAS}

1. Haagedoorn EML, Oldhoff J, Bender W, Clarke WD, Sleijfer DT. Oncologia básica para profissionais de saúde. São Paulo (SP): Associação Paulista de Medicina; 2000.

2. Ward JD. Pediatric cancer survivors: assessment of late effects. Nurse Practitioner 2000; 25(12):18-36.

3. Mendonça N. Porque o câncer deve ser considerado como doença "própria da infância". Pediatria 2000; 76(4):261-2.

4. Bricarello S. O câncer da criança (editorial). Pediatria Moderna 1999; 35(12).

5. Instituto Nacional de Câncer. Câncer infantil. [on line] 2003 [citado em 05 de março de 2003]. Disponível em http://www.inca.org.br.

6. Bonassa EMA. Enfermagem em terapêutica oncológica. $2^{2 a}$ ed. São Paulo (SP): Atheneu; 2000. relatadas pelos participantes; porém elas eram acompanhadas de sugestões para minimizá-las. Nesse sentido, as alternativas mencionadas para o enfrentamento foram a companhia dos pais, o apoio dos profissionais e a fé em Deus.

A crença de que as crianças possuem pouca competência para narrar suas experiências tem levado seus pais ou cuidadores a serem os informantes, no entanto alguns autores ${ }^{(24-25)}$ consideram que as crianças são as melhores fontes de informação sobre o que ocorre com elas mesmas. Nesse sentido, vimos que os resultados da presente pesquisa coincidem com tal argumentação.

O tratamento da criança e do adolescente com câncer deve ser abrangente, merecendo atenção não só as necessidades físicas, como também as necessidades psicológicas e sociais, incluindo personalização da assistência, promoção de cuidados atraumáticos e direito à informação. Então, disponibilizar à criança/adolescente informações sobre a doença e o tratamento; prepará-la para receber os procedimentos; adotar medidas para o alívio da dor e desconforto; incluir a família no processo de cuidado, como também salvaguardar a tomada de decisão da família, da criança e do adolescente, podem promover a auto-estima de todos que vivem esse processo.

Como desdobramento do presente trabalho, elaboraremos, embasados na vivência das crianças e dos adolescentes, uma cartilha de orientação intitulada "Quimioterapia intratecal: vivências de crianças e adolescentes".

Considerando que não encontramos nas bases de dados MEDLINE E LILACS nenhuma pesquisa que abordasse os cuidados de enfermagem na administração da quimioterapia intratecal, recomendamos a elaboração de outras pesquisas para ampliar a compreensão desse processo para além dos aspectos da terapêutica medicamentosa.

7. Chaud MN, Peterlini MAS, Harada MJCS, Pereira SR. O cotidiano da prática de enfermagem pediátrica. São Paulo (SP): Atheneu; 1999. 8. Ishibashi A. The needs of children and adolescents with cancer for information and social support. Cancer Nurs 2001; 24(1):61-7.

9. Baum F. Research to support health promotion based on communily development approaches. In: Colquhound A, Kellehear A, organizadoras. Health research in pratice. London (England): Chapmam \& Hall; 1996. v.2.

10. Darbyshire P, Haller A, Fleming S. The interstellar cold: parents experiences of their children in palliative care. Reporter prepared for the South Australian Health Commission, Palliative Care Program Australia; 1997. 122p.

11. Ministério da Saúde (BR). Manual operacional para comitês de ética em pesquisa. Brasília (DF): Ministério da Saúde; 2002.

12. Bock AMB. Psicologias: uma introdução ao estudo de psicologia. São Paulo (SP): Saraiva; 1999. 
13. Goldenberg M. A arte de pesquisar: como fazer pesquisa qualitativa em ciências sociais. São Paulo (SP): Record; 1999.

14. Cauhé AS. Entrevista e questionário. In: Baztan AA, organizadores. Etiografia: metodologia cualitativa en la investigación sociocultural. Barcelona (ESP): Marcambo; 1995.

15. Minayo MCS. O desafio do conhecimento: pesquisa qualitativa em saúde. São Paulo (SP): HUCITEC; 1992.

16. Dupas G, Caliri MHL, Franciosi MC. Percepções de enfermeiras de uma instituição hospitalar sobre a assistência prestada a família e a criança portadora de câncer. Rev Bras Cancerol 1998; 44(4):327-34. 17. Brandão L. Psicologia hospitalar: uma abordagem holística e fenomenológica-existencial. Campinas (SP): Editora Livro Pleno; 2000. 18. Menossi MJ, Lima RAG. A problemática do sofrimento: percepção do adolescente com câncer. Rev Esc Enfermagem USP 2000; 34(1):4551.

19. Tetelbom M. A criança com doença crônica e sua família: importância da avaliação psicossocial. Pediatria 1993; 60(1):5-11.

20. Costa JC, Lima RAG. Crianças/adolescentes em quimioterapia ambulatorial: implicações para a enfermagem. Rev Latino-am Enfermagem 2002 maio-junho; 10(3):20-5.

21. Françoso LPC. Vivências de crianças com câncer no Grupo de Apoio Psicológico: Estudo Fenomenológico. [tese] Ribeirão Preto (SP): Faculdade de Filosofia, Ciências e Letras/USP; 2002.

22. Vieira MA, Lima RAG. Crianças e adolescentes com doença crônica: convivendo com mudanças. Rev Latino-am Enfermagem 2002 julho-agosto; 10(4):552-60.

23. O' Neill DP, Kenny EK. Spirituality and chronic illness. Image: Nurs Scholarship 1998; 30(3):275-80.

24. Blarison D. They never want to tell you: children talk about câncer. Cambridg (ENG): Harvard University Press; 1991.

25. Faux AS, Walsh M, Deatrick JA. Intensive interviewing with children and adolescent. West J Nurs Res 1988; 10(2):180-94. 